\title{
Multiple Nucleotide Abnormalities
}

National Cancer Institute

\section{Source}

National Cancer Institute. Multiple Nucleotide Abnormalities. NCI Thesaurus. Code C45654.

Point mutations at various locations in a DNA sequence from either a eukaryotic or prokaryotic organism that causes a base change which results in an amino acid change in the protein product. This alteration may affect the stability and/or activity of the protein. Multiple mutation abnormalities may be heritable or occur spontaneously. 